\title{
35 千伏变电站在线监测与状态检修
}

\author{
吴鹏飞 赵莹颖
}

国网河南省电力公司遂平县供电公司

DOI:10.32629/hwr.v2i12.1789

[摘 要] 本文系统阐述了 35 千伏智能化变电站在线监测的构成。一次设备的在线监测主要通过状态监测终端装置和就地智 能化设备完成, 二次设备的状态监测主要由综合自动化系统完成全站的控制、信号及测量功能。为下一步 35 千伏常规变电站 开展智能化改造提供参考。

[关键词] 在线监测; 状态检修; 智能化; 数据采集

35 千伏智能化变电站的意义在于强化全寿命周期管理 概念, 合理应用电网建设新技术成果, 并结合工程具体情况 进行优化。主要原则为: 选用有利于降低全寿命周期运行成 本的设备, 加强状态在线监测, 实时掌握设备的运行状态, 及 时将设备管理的关口从后期检修前移至前期隐患治理整改, 以提高供电可靠性、尽量减少设备维修维护工作。

\section{1 状态检修的技术特点}

根据“国家电网公司电网设备状态检修管理规定”得知, 设备的状态检修工作应具备 “安全第一”、“标准先行”、“应 修必修”、“过程管控”、“持续完善”, 技术特点包括设备信
息收集、设备状态评价、风险评估、检修决策、检修计划、 检修实施及绩效评价, 核心在于利用各类监测手段, 掌握设 备的状态信息, 根据这些信息合理安排检修计划。与故障检 修相比, 将检修的关口前移, 避免设备、电网出现事故, 减少 安全隐患, 提高设备运行可靠性; 由于电网规模的进一步扩 大, 所有设备定期检修周期过长, 因此与定期检修相比, 避免 了部分设备的 “失修” 和 “过修” 的情况发生。在实际应用 中, 应将状态检修与定期检修相结合, 根据设备运行条件而 选择实际的检修策略。

\section{5 千伏智能变电站的技术特点}

功率这些投切物理量中最好选择无功功率作为投切参数物 理量。(3) 在很早以前的补偿电容组中电容器的分担方式和 投切开关的方式普遍采用等容量分组和循环投切; 后来又采 用了按比例分配、按编码配置、投切开关按级投切。但是这 些方式都不能达到我们想要的补偿效果。

\section{4 结束语}

总之, 现今国家强烈要求发展 “节能经济” 的大好形势, 有志于发展 “节能经济”与 “节能经济” 的中国 “工业自动 化” 的企业与单位, 应当坚持 “节能” 理念。国家也已经注 意制定发展 “节能经济” 的战略, 制定优惠发展 “节能经济” 企业的政策, 并积极支持 “节能经济” 的研发。同时, 也应看 到, 我国在 “节能技术” 领域里的自主创新能力正在快速提 高, 新的更有效的 “节能技术” 正在国家的大力支持下研发 出来, 并被产业化应用。中国电气自动化的企业与单位, 应当 奋发图强迎接挑战, 使电气自动化技术及其产品为 “节能经 济”发展战略增辉!

\section{[参考文献]}

[1]周丹.我国工业电气自动化的发展现状与趋势[J].科 技创新导报,2008(17):115.

[2]孙柏林.中国自动化与可持续发展一一自动化技术进入 “低碳经济”新时代[J].自动化博览,2010,27(01):42-47.

[3]罗光明,汪洋.电气自动化节能设计技术研究 [J]. 居 舍,2018(15):188+184. 电抗器, 滤除线路上的谐波。(2) 为了有效的防止投切振荡、 过补偿和无功倒送, 在电容器的功率参数、无功电流、无功 
35 千伏智能化变电站自动化系统是按照 IEC61850 的面 向对象和分层分布思想构建，在站控层、间隔层实现 IEC61850 的自动化系统。

(1) 装设有计算机监控系统, 为避免设备重复设置和功 能相互覆盖, 站内不设置专用的远动装置, 远动装置的计算 机和监控系统统一考虑, 远动信息由站内计算机监控系统统 一采集和传送。

(2) $35 \mathrm{kV} 、 10 \mathrm{kV}$ 侧数据采集全部采用电压电流组合式电 子互感器, 变电站内采用标准的 IEC61850 通信协议, 间隔层 与过程层设备采用网络化 GOOSE 控制。

(3) 过程层采用合并单元与智能终端一体化的装置实现, 直接安装在高压柜面板上或户外智能终端箱内。

(4) 间隔层保护采用全站集成的站域保护控制主机, 能 在一台主机上实现全站保护、控制、测量及优化控制等操 作, 为了提高可靠性, 采用双机咒余配置。站控层与间隔层 之间组常规以太网, 全部运行 IEC61850 协议, 断路器智能 控制单元、合并器单元、间隔层设备之间组双 GOOSE 光纤 以太网。所有 GOOSE 及常规交换机应同时支持交流、直流 供电。

(5) 全站的五防闭锁功能及小电流接地选线功能由站内 计算机监控系统实现, 不单独设置。智能站采用 IRIG-B 码对 时, 它技术成熟, 精度可以达到微秒级。

\section{5 千伏智能变电站在线监测与状态检修的实现}

(1) 一次设备部分。35 千伏智能变电站一次设备状态监 测主要通过状态监测终端装置和就地智能化设备完成, 由智 能单元实现在线监测特征量的采集。(1) $35 \mathrm{kV}$ 开关柜部分: $35 \mathrm{kV}$ 进出线、站用变间隔均配置单台智能组件, 下放于各开 关柜内。各智能组件应支持 DL/T860 规约, 含保护、测控、 开关柜温度、分合闸电流、分合闸时间、储能电机状态等功 能。在开关触头、母线接头、电缆接头等处配置无线测温终 端, 配置避雷器和温度集中的采集装置一套, 可在线监测断 路器开关位置信号; 避雷器的泄露电流, 动作次数, 开关柜温 度; (2) $10 \mathrm{kV}$ 开关柜部分： $10 \mathrm{kV}$ 主变和出线间隔均配置单台 智能组件, 下放于各开关柜内。各智能组件应支持 DL/T860 规约, 含保护、测控、开关柜温度、分合闸电流、分合闸时 间、储能电机状态等功能。在开关触头、母线接头、电缆接 头等处配置无线测温终端。可在线监测电缆接头温度。

(2) 二次设备部分。 35 千伏智能变电站二次设备在线监 测采用综合自动化装置, 由综合自动化系统完成全站的控 制、信号及测量功能。智能化变电站是由智能化一次设备和 网络化二次设备分层构建, 建立在 IEC61850 通信规范基础 之上, 能够实现变电站内智能电气设备间信息共享和互操作 的现代化变电站。由电子式互感器、智能化开关设备、网络
化的二次设备、IEC61850 的应用等要素组成。(1)变压器保 护配置双重化的主后一体化保护测控装置, 非电量保护单独 设置。配置高、低压侧智能终端各 1 套, 可将主变高、低压 侧 CT 信号和 PT 信号转换成数字信号后送主变保护装置, 安 装于开关柜上。配置主变本体智能终端箱一面 (内含主变智 能单元、非电量保护及有载调压控制等), 安装于主变压器附 近。非电量遵循国网要求直采直跳。变压器主保护有瓦斯保 护及差动保护。后备保护在高压侧装设复合电压闭锁方向过 流以及过流保护, 两段零序过流保护。低压侧装设复合电压 闭锁过流保护, 另外在高、低压侧装设过负荷保护。(2) $35 \mathrm{kV}$ 、 $10 \mathrm{kV}$ 线路保护配有三相式电流速断、过流保护及重合闸和 低周减载功能。 $10 \mathrm{kV}$ 电容器保护配有三相式电流速断、过 流保护、开口三角电压保护、过压及失压保护。(3)以上保护 测控均由变电站集成站域保护控制主机实现。变电站集成站 域保护控制主机能够利用全站数据进行综合保护、测量与控 制, 是实现变电站智能化的重要设备。装置采用 $100 / 1000 \mathrm{M}$ 以太网接口通过采样值网络得到全站的采样数据, GOOSE 网 络得到全站的状态信息, 并能通过 GOOSE 网络实现对所有开 关设备的操作与控制。(4)站域保护控制装置配置大屏幕彩色 液晶显示屏, 显示与操作风格与监控系统相似, 能清晰的显 示一次系统的接线方式和运行状态, 并能在主接线图上对间 隔进行信息查询、定值操作、压板操作、控制操作及检修状 态设置。(5)电能表采用数字式电能表, 采用 RS485 实现组网。 为了减少电缆数量 $35 \mathrm{kV} 、 10 \mathrm{kV}$ 电能表分散安装于相应开关 柜上。

通过以上信息的状态在线监测, 可以有效获取相应设备 的设备状态, 从而实现设备的状态检修。

\section{4 结束语}

目前 35 千伏智能变电站的在线监测与状态检修仍然处 于发展阶段, 各项技术仍有进一步的发展空间。未来, 35 千 伏智能变电站和电网状态检修技术的进一步发展, 技术更加 成熟之后, 设备检修将依托在线监测技术, 结合可靠的辅助 决策系统, 实现手工向自动, 自动向智能化的发展, 电网设备 运行将更加可靠。

\section{[参考文献]}

[1]高翔.智能变电站建设技术 [M].北京:中国电力出版 社,2012:36.

[2]彭双剑,刘武林,刘复平,等.智能变电站在线监测系统 应用现状及建议[J].湖南电力,2013(s1):40-42.

[3] 林 禹粀.智能变电站的规划与建设 [D]. 吉林大 学, 2013(04):53.

[4]张红平.智能变电站状态检修的实现 [J].中国科技纵 横,2013(23): 143. 